\title{
Eksistensi Kalender Bali dalam Kultur Sosial Masyarakat Multireligius Bali
}

\section{Fajri Zulia Ramdhani ${ }^{1, *}$}

1 Universitas Islam Negeri Sunan Ampel, Indonesia; e-mail: fajrizuliar@gmail.com

* Correspondence

Received: 2020-03-17; Accepted: 2020-05-27; Published: 2020-05-30

\begin{abstract}
The Balinese calendar is a local Indonesian genius that still exists today. Although identical with Hindu religious rites, the Balinese calendar is also used in the daily activities of the whole community. Because its content consists of information that is not found in the calendar that spread nationally. With regard to the social culture present in this Balinese multireligious society, the Balinese calendar then becomes an interesting discussion. This paper aims to enrich the treasury of the Balinese calendar discourse in the community's social culture. So this article contains how the history of the Balinese calendar and the contents contained therein. Also, its existence in various sectors is urgent especially in the social culture of a multireligious community. The method used in this study is library research by examining various documents and scientific works, as well as interviews with Muslim community's leaders in the Klungkung, Bali. This paper describes the conclusion that the Balinese calendar was known at the time of the great tradition-oriented to Hindu religion and culture. The Balinese calendar contains at least some dating systems such as AD, Hijri, Chinese, Balinese Caka, Islamic Java, Tiki, and Pawukon. The Balinese calendar is used in inter-community cultural-social affairs such as determining good days in various fields, knowing market days, understanding holidays that only apply in the Bali area, and so on.
\end{abstract}

Keywords: Balinese calendar; Multireligious; Culture; Social; Bali.

Abstrak: Kalender Bali merupakan local genius Indonesia yang tetap eksis penggunaanya hingga kini. Meski identik dengan ritus religius umat Hindu, kalender Bali juga digunakan dalam aktifitas harian masyarakat keseluruhan. Karena dalam muatan kalender Bali, terdapat informasi yang tidak dijumpai dalam kalender yang tersebar secara nasional. Berkaitan dengan kultur-sosial yang hadir dalam masyarakat multireligius Bali inilah, kalender Bali kemudian menjadi sebuah bahasan yang menarik. Tulisan ini bertujuan untuk memperkaya khazanah diskursus kalender Bali dalam kultursosial masyarakatnya. Sehingga tulisan ini memuat bagaimana sejarah dan perkembangan kalender Bali dan muatan juga peristilahan yang terdapat di dalamnya. Juga eksistensinya dalam berbagai sektor urgen khususnya pada kultur-sosial masyarakat yang multireligius. Tulisan ini menggunakan metode penelitian pustaka dengan menelaah berbagai dokumen dan karya ilmiah, juga wawancara dengan tokoh masyarakat Muslim di daerah Klungkung, Bali. Tulisan ini menghasilkan kesimpulan bahwa kalender Bali dikenal pada masa tradisi besar yang berorientasi pada agama Hindu dan kebudayaannya. Kalender Bali setidaknya memuat beberapa sistem penanggalan seperti Masehi, Hijriah, Cina, Caka Bali, Jawa Islam, Tiki, dan Pawukon. Kalender Bali digunakan dalam urusan kultur-sosial antarmasyarakat seperti penentuan hari baik dalam berbagai bidang, mengetahui hari pasar, memahami hari libur yang hanya berlaku di daerah Bali, dan sebagainya.

Kata Kunci: Kalender Bali; Multireligius; Kultur; Sosial; Bali. 


\section{Pendahuluan}

Kalender Bali merupakan local genius Indonesia yang tetap eksis penggunaannya hingga kini. Identitas Hindu dalam kalender Bali berkaitan dengan urgensi aspek religiusitasnya, membawa anggapan ekslusivitas. Bali disebut sebagai enklave Hindu Indonesia, hal ini berdasar kepada mayoritas kepercayaan penduduknya adalah beragama Hindu. Sensus penduduk terakhir pada tahun 2010 (Badan Pusat Statistik Provinsi Bali, 2018b), menyebutkan angka 3.247.283 jiwa beragama Hindu dengan total jiwa adalah 3.890.757 jiwa. Meski demikian, komunitas etnis lainnya telah menjadi bagian dari peradaban Bali sejak lama. Multireligius di Bali berangkat dari kontak etnis sehingga menjadikan Bali tidak hanya multikultural juga multireligius.

Dalam masyarakat berperadaban tinggi, kalender menjadi urgensi tersendiri yang dibutuhkan tidak hanya pada ranah sosial, namun juga agraria, politik, ekonomi, hingga religius yang digunakan mencatat kejadian-kejadian penting dalam suatu masa (Aveni \& Hartung, 1986; Muh Bashori, 2013; Sorokin \& Merton, 1937). Kalender merupakan sistem pengorganisasian satuan waktu yang bertujuan untuk perhitungan dan penandaan waktu dalam kurun yang lama (Azhari, 2005; Davenport, 2007; Hidayatullah, 2018). Senada dengan pengertian tersebut, kalender Bali merupakan organisasi waktu yang berdasar pada Solar, Lunar, Luni-Solar, dan Aritmatika (Hidayatullah, 2018; Ramdhani, 2017; Rohmah, 2019). Hal ini karena muatan dalam kalender Bali tidak hanya berdasar pada satu penanggalan saja, namun berbagai penanggalan seperti Masehi, Hijriyah, Jawa Islam, Cina, Caka Bali, Pawukon, dan sebagainya.

Kalender Bali tidak hanya sebuah kearifan lokal, namun secara fungsional mengatur urusan tidak hanya pada interagama Hindu, namun juga hingga pada aspek antarumat beragama. Hal ini tentu menjadi sebuah antitesis terhadap dogma yang berkembang mengenai kalender Bali yang sarat dengan aktivitas keagamaan Hindu. Karena realitas di masyarakat Bali secara keseluruhan tanpa terbatas etnis dan agama menggunakannya dalam keseharian.

Pembahasan dalam ranah kalender Bali dan hubungan kultur-sosial yang dipengaruhinya, belum ramai dibahas dalam ruang diskusi publik dan akademis. Kalender Bali secara utuh pernah dibahas oleh Chatterje (1997) yang di dalamnya memaparkan mengenai muatan kalender Bali yang ditulis oleh K. Kebek Sukarsa. Salah satu muatan kalender Bali yaitu kalender Pawukon di bahas oleh Ramdhani (2017). Selain itu, muatan lain yaitu kalender Caka Bali dibahas oleh Mutamakin (2018). Dua muatan ini hanya membahas sebagian dari kalender Bali namun dalam perspektif astronomi. Penelitian lainnya mengenai kearifan lokal antaragama di Bali oleh Sulistiono (2018) yang membahas konsep menyama braya. Kalender Bali khususnya Kalender Pawukon dan Caka Bali secara sosio-kultural hanya dalam lingkup masyarakat Hindu Bali sudah dibahas oleh Ginaya (2018). Sedangkan Swandana (2017) melakukan penelitian mengenai pemaknaan tanda dalam Ala Ayuning Dewasa berdasarkan Wewaran pada kalender Caka Bali. Meski sama membahas Ala Ayuning Dewasa, namun aspek yang penulis bahas adalah maksud penggunaan calendar sedangkan penelitian Swandana adalah mengenai pemaknaan tanda. Kesemua literatur tersebut tentu menjadi berbeda dengan pembahasan dalam penelitian ini yang akan membahas Kalender Bali dan hubungan kultur-sosial yang melingkupinya pada masyarakat multireligius Bali. Sehingga penelitian ini adalah sebuah kebaruan yang belum pernah dibahas sebelumnya.

\section{Hasil dan Pembahasan}

\section{Sejarah dan Perkembangan Kalender Bali}

Kalender atau penanggalan Bali dalam pembabakan sejarah Bali, dikenal sejak masa tradisi besar. Orientasi dari tradisi tersebut adalah agama dan budaya Hindu. Tradisi besar dicirikan sebagaimana pendapat Swellengrebel (1960) berisi sentralisasi kekuasaan, sakralitas raja sebagai keturunan dewa, perisitilahan tokoh Pedanda, penulisan lontar dalam kajian keagamaan, klasifikasi kasta, adanya upacara ngaben, hadirnya sistem penanggalan Hindu-Jawa, pertunjukan wayang kulit dan tarian topeng, perkembangan arsitektur dan kesenian bermotif Hindu dan Budha (Suarka, 2008). Kuntjaraningrat melihat kebudayaan dari tiga wujud, sebagai organisasi ide, tingkah laku, dan entitas 
budaya (Kahmad, 2009). Kalender merupakan salah satu produk budaya, karena merupakan sebuah organisasi ide yang terealisasi dan terdokumentasi dalam sebuah sistem penanggalan sehingga menjadi sebuah entitas.

India dengan pengaruh agamanya yakni Hindu dan Budha pada abad ke VIII dan XIII Masehi turut memperkaya khazanah kebudayaan Indonesia, salah satunya dalam aspek penanggalan (Chatterjee, 1997). Meski terdapat rekonstruksi kalender Jawa, namun kalender Saka yang merupakan akulturasi budaya India dan Jawa serta kalender Pawukon khas Indonesia telah digunakan di Bali sejak sekitar abad ke XIV. Hal ini merupakan salah satu dampak invasi dan kekuasaan politik Majapahit. Kalender tersebut kemudian menjadi berkembang dengan kekhasan masing-masing daerah, setelah Bali merdeka dari Majapahit dan memiliki sistem kerajaannya sendiri. Sehingga sekitar sembilan kerajaan di Bali memiliki sistem penanggalannya secara mandiri (Ramdhani, 2017).

Pada abad ke XX yakni ketika Belanda menguasai Indonesia, diadakanlah upaya unifikasi kalender. Hal ini dimaksudkan oleh Belanda untuk kepentingan aspek pariwisata, sedangkan bagi masyarakat Hindu dalam hal ini diwakili oleh para tokoh, digunakan untuk penyatuan presepsi waktu diadakannya upacara. Upaya unifikasi kalender dilakukan sejak sekitar tahun 1930-an, menghasilkan rekonstruksi kalender yang diberi nama Penampih Sasih Karo dan Kawulu. Hasil rekonstruksi ini dimaksudkan untuk penyesuaian jatuhnya purnama kartika (sasih kapat) dan purnama waisaka (sasih kadasa). Sehingga dua purnama ini pada terjadi dalam hitungan yang tepat, dan juga korelasinya dengan pelaksanaan aktifitas (Ramdhani, 2017). Kalender dalam fungsinya memiliki kriteria kemapanan jika memenuhi syarat berikut, batasan keberlakuan, ditetapkan oleh otoritas tunggal, dan konsistensi kriteria yang disepakati (Azhari, 2015). Dalam perkembangan kalender ini, dari desentralisasi kriteria menuju sentralisasi, merupakan sebuah upaya menuju konsep kemapanan. Menyamakan presepsi dan konsepsi waktu dari berbagai tokoh agama Hindu yang tersebar diseluruh Bali tidak hanya memberikan pengaruh pada aspek religius namun juga aspek politik dan pariwisata kala itu.

Setelah rekontruksi pertama tersebut, kemudian terjadi berbagai pengembangan dan rekonstruksi lanjutan. Rekonstruksi pertama Penampih Sasih Karo dan Kawulu digunakan sejak 1935-1940 dengan sistem Pangalantaka-nya adalah Eka Sungsang ka Kliwon (Prawira et al., 2015). Pangalantaka merupakan sistem penyesuaian tibanya tilem dan purnama dengan perhitungan matematis dengan kenyataan astronomis. Sistem pangalantaka menghasilkan penyesuaian umur bulan tidak hanya berusia 30 hari namun juga 29 hari. Pangalantaka dilaksanakan pada interval 9 wuku, yakni pada wuku Sungsang, Tambir, Kulawu, Wariga, Pahang, dan Bala (Prawira et al., 2015). Rekonstruksi kedua adalah pada kisaran tahun 1950. Dimana Bangbang Gde Rawi dan timnya menggagas Pengerepeting Sasih dengan Mala Jhista atau Mala Sadha. Dimana setiap periode tahun panjang digunakan Pangalantaka Eka Sungsang ka Pon. Dengan dasar inilah Parisada Hindu Dharma Indonesia (PHDI) menggunakannya dalam landasan hari suci Hindu, seperti Nyepi yang kemudian sejak tahun 1960-an diperingati secara bersamaan (Prawira et al., 2015).

Tahun 1991, oleh PHDI Pusat yang diketuai oleh Ida Pedanda Putra Telaga ingin meninjau kembali pola penampih sasih sebelumnya dengan memafhumi Lontar Wariga milik Ketua PHDI Pusat yang berisikan penampih sasih berkeseimbangan sebagai ganti dari penampih sasih berkesinambungan (Ramdhani, 2017). Di tahun 1993, dibentuk tim pengkaji wariga dengan ketua adalah I Ketut Kabek Sukarsa yang merekonstruksi kalender Bali dengan sistem Nirayana dengan Nampih Sasih berkeseimbangan yang digunakan tiap tahun panjang. Adapun enam Sasih Penampih yang digunakan yaitu, Jhista, Sadha, Kaesa, Karo, Katiga, dan Kadasa. Pada rekonstruksi ketiga ini, dinyatakan berlaku di tahun 1991 melalui Mahasabha PHDI Pusat dan tidak berlaku lagi melalui kesepakatan Sabha Pandita PHDI Bali tentang Penampih Sasih di 18 September 2001 (Prawira et al., 2015).

Sebelumnya di tahun 1998 Paruman Sulinggih PHDI Besakih memutuskan untuk menggunakan Pangalantaka Eka Sungsang ka Paing. Dan kemudian di tahun 2001, Paruman Sulinggih PHDI Bali dengan mengembalikan sistem kepada Pengerepeting Sasih dengan Mala Jhista atau Mala Sadha yang berlaku sejak 2003 (Prawira et al., 2015). Perkembangan kalender Bali ini tidak hanya sebuah fenomena budaya, namun juga usaha dalam menemukan dan menentukan kriteria terbaik dari kalender Bali. Perubahan 
terus terjadi sebagai sebuah keterbukaan budaya terdapat berbagai perkembangan dan penemuan pengetahuan oleh para tokoh dan penyusun kalender.

Kalender Bali secara utuh yang beredar kini secara luas di Bali pertama kali disusun oleh Ketut Bangbang Gde Rawi. Dilahirkan di desa Celuk, Sukawati, Gianyar, Bali pada 17 September 1910. Ketekunannya dalam mempelajari hal ihwal wariga, mencari lontar, berdiskusi dengan pedanda membawanya memafhumi keilmuan waktu dengan baik. Ketekunan ini dilakukannya setelah menamatkan pendidikan tahun 1929 di sekolah Goebernemen Negeri Sukawati. Sekitar tahun 1940, ia menjadi perbekel di desa Celuk. Warisan dan pengetahuannya akan lontar membawa ia terkenal dalam permasalahan mengenai hari baik dalam pelaksanaan waktu upacara atau kegiatan adat. Bahkan tokoh adat dan agama Gianyar memintanya untuk menyusun kalender, namun ia tolak. Kisaran tahun 19481949 diselenggarakan rapat sulinggih Bali-Lombok yang memutuskan untuk mempercayakan Bangbang Gde Rawi dalam penyusunan kalender Bali. Setahun berselang, dengan dorongan dari Ida Pedanda Made Kemenuh, Ketua Paruman Pandita Bali-Lombok, Ia pun mulai menyusun kalender. Kalender hasil karya pertamanya dicetak oleh Pustaka Balimas (Ramdhani, 2017).

Hasil penyusunan kalender Bali oleh Ketut Bangbang Gde Rawi, kekhasan desain, tata letak, dan muatan di dalamnya menjadi citra tersendiri yang hingga kini tidak terpisahkan dari kalender Bali. Karena buktinya, hingga kini kalender sebagaimana yang telah disusun oleh Gde Rawi dan telah paten sejak 2002 (Ramdhani, 2017). menjadi gambaran paling umum pada berbagai kalender Bali dengan ragam penyusun. Secara khusus, kalender Bali yang akan dibahas dalam tulisan ini merupakan Kalender Bali terakhir yang telah terhimpun dari berbagai sistem penanggalan dan digunakan dewasa ini. Kalender Bali tersebut disusun tidak hanya oleh satu penyusun, namun dengan ragam penyusun seperti Ketut Bangbang Gde Rawi, I Gede Marayana, Wayan Gina, Kebek Sukarsa, I Made Bija.

\section{Kalender Bali dalam Muatan dan Peristilahan}

Banyaknya penyusun dan ragam kalender Bali yang beredar di masyarakat, penulis akan menfokuskan pada kalender Bali yang disusun oleh Wayan Gina dengan kalender tahun 2019. Komposisi kalender antarpenyusun tidaklah memiliki perbedaan signifikan, sehingga memafhumi salah satu kalender cukup dapat menginterpretasikan keseluruhan kalender Bali. Jika menengok ke dalam kalender, terdapat berbagai muatan informasi yang memenuhi ruang dari kertas yang digunakan. Bahkan tidak hanya itu beberapa lembar bagian belakang, pun tidak luput memuat berbagai penjelasan informasi tambahan. Sehingga kalender Bali sekilas akan terlihat padat tulisan dengan latar putih dan tulisan huruf hitam dan merah. Kalender Bali diawali dari bulan Januari hingga Desember dengan jumlah 12 lembar.

Bagian atas dari kalender Bali diawali secara berurutan dari kiri ke kanan adalah nama kalender yang terhimpun di dalam kalender Bali lengkap dengan informasi terkait yang terjadi pada bulan Masehinya. Diantara kalender tersebut adalah didominasi dengan font kalender Masehi, kemudian berturut-turut adalah kalender Saka/ Caka, Imlek/ Cina, Budha, Jawa, dan Hijriah. Hal ini menurut penulis memberikan aspek universalitas karena kemudahan akses ragam kalender.

Sebagai contoh pada bulan Januari 2019, tahun Caka-nya adalah 1940 yang pada bulan tersebut bertepatan dengan sasih Kapitu ngunya Kalima dan Kaulu ngunya Kanem. Maksudnya adalah pada bulan Januari 2019 bertepatan dengan sasih Kapitu dan Kaulu. Kata ngunya yang dimaksud merupakan pangunyan yang menunjukkan perubahan sifat bulan yang dimaksud. Dalam 12 sasih pada Kalender Caka dibagi menjadi 2 musim, yaitu musim kemarau dan penghujan. Sasih yang termasuk dalam musim kemarau adalah Kasa, Karo, Katiga, Kapat, Desta, Sada. Sedangkan bulan lainnya yaitu, Kalima, Kanem, Kapitu, Kaulu, Kasanga, dan Kadasa adalah musim penghujan (Mutamakin, 2018).

Kalender Caka Bali merupakan kalender Luni Solar dengan penambahan berbagai unsur lokal. Kalender ini berusia 12 bulan dengan masing-masing berisi 30 atau 29 tithi (hari dalam kalender Saka Bali dengan waktu variatif antara 20-27 jam). Sebagaimana dijelaskan sebelumnya, dalam tithi tersebut dibagi menjadi dua yaitu penanggal dan panglong. Dalam satu sasih atau bulan, terbagi menjadi 2 fase yaitu penanggal dan panglong. Penanggal merupakan fase dari bulan baru menuju bulan purnama. Dan panglong adalah dari bulan purnama menuju bulan mati/ tilem. Penanggal juga disebut dengan istilah 
suklapaksa dan panglong disebut juga kresnapaksa.(Mutamakin, 2018) Sehingga dalam jangka 30/ 29 tithi tersebut terbagi menjadi penanggal 1-14/15 hari yang dituliskan dengan tinta merah dan panglong 114/15 hari yang dituliskan dengan tinta hitam. Berikut adalah nama-nama bulan/ sasih pada kalender Saka Bali yaitu, Kasa, Karo, Katiga, Kapat, Kalima, Kanem, Kapitu, Kaulu, Kasanga, Kadasa, Desta, dan Sada (Chatterjee, 1997). Nampih Sasih adalah interkalasi pada kalender Luni Solar (Ramdhani, 2017). Artinya adalah bulan ke-13 untuk penyesuaian antara kalender Solar dan Lunar yang digunakan bersamaan.

Kemudian disebelahnya adalah tulisan Kong Hu Cu, Bouw sut 2569 Shio Kao/ Anjing XI-XII, Cap It Gwee - Cap Ji Gwee. Kalender Cina/ Imlek ini merupakan kalender Luni Solar. Dimana terdiri dari 12 bulan, Cia Gwee, Jie Gwee, Sa Gwee, Si Gwee, Go Gwee, Lak Gwee, Cit Gwee, Pe Gwee, Kauw Gwee, Cap Gwee, Cap It Gwee, Cap Jie. Penambahan interkalasi waktu yaitu bulan ke-13 mengikuti nama bulan sebelumnya dengan penambahan kata lun sebelum nama bulan (Firdaus, 2012). Selanjutnya adalah Budha, Parinibbana 2562. Kalender Budha ini dihitung sejak kematian Budha (Chatterjee, 1997).

Kalender Masehi merupakan kalender Solar yang yang siklusnya berdasarkan gerak semu Matahari Memiliki jumlah hari 365 pada tahun pendek, dan 366 hari pada tahun panjang. Satu siklusnya adalah 4 tahun dengan komposisi 3 tahun pendek dan 1 tahun panjang yang jumlah total 1461 hari (Khazin, 2008). Kalender Jawa tertulis Windu Sangara BE - 1952 B. Mulud-J. Awal. Windu Sangara merupakan salah satu siklus windu di Jawa yang terdiri dari Windu Adi, Kuntara, Sangara, dan Sancaya. Tahun Jawa terdiri dari 12 bulan yaitu Sura, Sapar, Mulud, Bakda Mulud, Jumadilawal, Jumadilakir, Rejeb, Ruwah, Pasa, Sawal, Sela, Besar.

Pada ujung kanan adalah tersebut Hijriah 1440 H, Rabiulawal-Jumadilawal. Merupakan kalender Lunar yang berdasar pada gerak bulan atas bumi. 1 tahunnya juga terdiri dari 12 bulan yaitu Muharam, Safar, Rabiulawal, Rabiulakhir, Jumadilawal, Jumadilakhir, Rajab, Syakban, Ramadan, Syawal, Zulkaidah, dan Zulhijah. Pada basithah berjumlah 354 hari dan kabisatnya adalah 355 hari. Satu siklusnya berjumlah 30 tahun dengan komposisi 11 tahun kabisat dan 19 tahun basithah (Nashirudin, 2013).

Selain kalender yang tersebut secara tekstual di atas, terdapat kalender yang terhimpun secara langsung di dalam kalender Bali seperti Kalender Pawukon. Kalender Pawukon berasal dari kata wuku yang merupakan istilah siklus dari kalender Pawukon yang berjumlah 7 hari di tiap wukunya. Sehingga total dalam satu siklus adalah 210 hari (Ramdhani, 2017). Wuku dalam Pawukon berjumlah 30 wuku yaitu, Sinta, Landep, Ukir, Kulantir, Tolu, Gumbreg, Wariga, Warigadean, Julungwangi, Sungsang, Dungulan, Kuningan, Langkir, Medangsia, Pujut, Pahang, Krulut, Merakih, Tambir, Medangkungan, Matal, Uye, Menail, Prangbakat, Bala, Ugu, Wayang, Kulawu, Dukut, Watugunung.

Pada bagian atas tanggal, di bawah penyebutan nama ragam kalender, terdapat nama-nama Wuku dalam kalender Pawukon. Sedangkan sebaliknya, pada bagian bawah yang diberi judul Ingkel berturut-turut adalah Mina, Manuk, Taru, Buku, Wong. Ingkel merupakan peristilahan dari hal-hal yang dianggap tidak patut dilakukan pada siklusnya. Ingkel berusia 42 hari dengan masing-masingnya berusia 7 hari. Pada minggu Mina berarti dilarang untuk menyakiti ikan, Manuk dilarang menyakiti unggas, Taru dilarang menebang pepohonan kayu, Buku dilarang menebang tanaman yang beruas, dan Wong dilarang menyakiti sesama manusia (Wiana, 2003).

Secara umum yang tersebar secara nasional umumnya kalender akan memuat paling banyak 4 jenis penanggalan yaitu, Masehi, Hijriah, Jawa, dan Cina. Kalender Bali menjadi sebuah keunikan karena menghimpun kalender sedemikian sehingga menjadi sebuah dokumentasi atas khazanah kalender dunia di Indonesia khususnya di Bali.

Selain jumlah kalender yang terhimpun di dalamnya, menariknya adalah penyebutan nama hari dalam satu pekan yang tergolong tidak hanya satu macam bahasa, namun dari ragam bahasa. Bahasa Indonesia adalah Minggu, Senin, Selasa, Rabu, Kamis, Jumat, Sabtu. Kemudian dalam bahasa Bali yang dikenal dengan Saptawara adalah Redite, Coma, Anggara, Buda, Wraspati, Sukra, Saniscara. Dan Saptawara selain digunakan tulisan latin, juga ditulis dalam aksara Bali. Kemudian dalam bahasa Inggris, Sunday, Monday, Tuesday, Wednesday, Thursday, Friday, Saturday. Dalam bahasa Jepang, Nichiyobi, Getsuyobi, Kayobi, Suiyobi, Mokuyobi, Kinyobi, Doyobi. Terakhir dalam bahasa Cina yang dituliskan, Sing Chi Rek, Sing Chi Ik, Shing Chi El, Sing Chi San, Sing Chi She, Sing Chi U, Sing Chi Lioek. 
Bagian inti kalender merupakan kotakan yang memuat dominan tanggal pada Masehi. Tanggal pada Masehi jumlahnya variatif tiap bulan yakni 31, 30, 28/29. Pada tanggal Masehi pada hari libur berwarna merah, sedangkan hari lainnya berwarna hitam. Selain tanggal Masehi, di dalamnya memuat ragam informasi yang terkesan mengelilingi tanggal Masehi. Diantaranya adalah, tanggal pada penanggal/ panglong pada Sasih di kalender Caka, tanggal pada kalender Hijriah, tanggal kalender Jawa, Wewaran, tanggal pada kalender Cina, Palalintangan, dan sebagainya.

Wewaran adalah satu diantara berbagai bahasan menarik dalam kalender Bali. Wewaran berasal dari kata wara yang berarti hari yang kemudian berarti kelompok hari. Secara umum kita mengenal istilah pengelompokan hari adalah berjumlah 7 hari. Namun Wewaran adalah 10 jenis penelompokan hari yang berjalan bersamaan. Dinamai dengan bahasa Sansekerta yaitu Ekawara, Dwiwara, Triwara, Caturwara, Pancawara, Sadawara, Saptawara, Astawara, Sangawara, dan Dasawara (Chatterjee, 1997). Kemudian secara rinci, masing-masing kelompok hari tersebut memiliki anggota hari yang juga mempunyai nama yang berbeda adalah sebagai berikut:

1. Ekawara: Luang

2. Dwiwara: Pepet, Menga

3. Triwara: Beteng, Kajeng, Pasah

4. Caturwara: Laba, Jaya, Mandala, Sri

5. Pancawara: Paing, Pon, Wage, Kliwon, Umanis

6. Sadawara: Aryang, Urukung, Paniron, Was, Maulu, Tungleh

7. Saptawara: Soma, Anggara, Buda, Vraspati, Sukra, Saniscara, Radite

8. Astawara: Indra, Guru, Yama, Ludra, Brahma, Kala, Uma, Sri

9. Sangawara: Jangur, Gigis, Mohan, Ogan, Erangan, Urungan, Tulus, Dadi, Dangu

10. Dasawara: Pati, Suka, Duka, Sri, Manuh, Manusa, Raja, Dewa, Raksasa, Pandita

Sedangkan Palalintangan adalah ramalan mengenai sifat dan watak seseorang. Hal ini didasarkan dengan pada perpaduan hari kelahiran di Saptawara dan Pancawara. Keseluruhannya berjumlah 35, yaitu Lintang sungsangkala, gajah, patrem, waluku/ tenggala, lawean/ goang, kelapa, kukus/ dupa, kiriman, lembu, pedati, puyung, kuda, yuyu, asu, jong sarat, dapat/ sidamalung, tangis, gajahmina, lumbung muyung, kartika, tiwa-tiwa, sangkatikel, salah ukur, bade, kumba, naga, angsa mekeem, bubu bosor/ bolong, perahu pegat, magelut/ gelut utang, udang, begong, ru/ panah, sugeng, puwuh atarung, dan pagelangan.

Diantara bagian dari jumlah hari dalam satu bulan diakhiri atau diawali dengan tampakan gambar penyusun kalender berupa foto formal hitam putih disertai daerah asal penyusun. Seperti Wayan Gina berasal dari Galiran, Karangasem. Kemudian menyesuaikan dengan kondisi jumlah hari, dijelaskan juga zodiak rasi bintang pada bulan tersebut, dan Pranatamangsa. Zodiak terdiri dari 12 rasi bintang yaitu Aries, Taurus, Gemini, Cancer, Leo, Virgo, Libra, Scorpio, Sagitarius, Capricorn, Aquarius, dan Pisces. Sedangkan Pranatamangsa adalah regulasi musim yang berdasar pada sistem edar semu Matahari, atau Solar System (Chatterjee, 1997). Selain itu, dijelaskan pula singkatan dari pemafhuman yang ada dalam kotakan tanggal. Sebagai contoh adalah B untuk Bakda, Ek. untuk Ekajalasari, G untuk Gwee, J untuk Jumadil, Kl untuk Kala, Lk untuk Laku, Lt untuk Lintang, Ps untuk Pratithi Samutpada, Pr untuk Pura, CJG untuk Cap Ji Gwee, dan sebagainya.

Dari temuan penulis di atas pada kalender Wayan Gina, terdapat beberapa perbedaan dengan kalender Kebek Sukarsa pada tulisan Chatterje (1997). Meski penelitian tersebut telah lama dilakukan, yakni di tahun 1997 ada kesamaan signifikan terkait penjelasan kalender mendetail yang belum dapat penulis temukan pada penelitian lainnya. Dalam penjelasan tersebut muatan kalender yang ditemukan adalah Kaliyuga Era, Imlek, Gengo, Budha Parinirvana, Vikrama, Masehi/ Christian Era, Caka, Saka Jawa, Hijriah, Pranata Mangsa. Kaliyuga Era terhimpun dimaksudkan adalah Kalender Pawukon, Kalender Solar Nirayana, Bumi atau Tahun Shavana, dan Kalender Bulan (Chatterjee, 1997). Yang pasti berbeda dalam kalender ini adalah kalender Gengo yang tidak dituliskan pada kalender milik Wayan Gina. Kalender Gengo merupakan sistem penanggalan milik Jepang yang dikenal di Jepang dengan istilah kigen atau koki. Hal ini merupakan akibat dari penjajahan oleh Jepang atas Indonesia sehingga kalendernya dimuat dalam kalender Bali. Namun, ternyata kalender ini sudah tidak lagi digunakan di Jepang setelah Perang Dunia ke II (Chatterjee, 1997). Berdasar pada hal tersebut, penulis beranggapan 
bahwa karena telah tidak digunakan lagi, menjadi salah satu pertimbangan tidak dicantumkannya kalender Gengo dewasa ini.

Sebagaimana kalender pada umumnya, kalender Bali pun di bagian bawahnya memuat informasi mengenai hari-hari istimewa dan libur. Namun, tidak hanya libur atau peringatan nasional juga internasional, namun juga hari raya/ rerainan Hindu, tanggal odalan di Pura, hari raya berbagai agama, ala ayuning dewasa, hari-hari baik dalam berbagai kegiatan dan pekerjaan seperti sektor pertanian, peternakan, perikanan, pembangunan, kerajinan, perekonomian, pendidikan, keamanan, kesehatan, asosiasi, dan upacara.

Ala Ayuning Dewasa merupakan baik buruknya suatu waktu. Hal ini berdasarkan kata ala berarti buruk, ayuning dari kata ayu yang berarti baik, dan dewasa memiliki arti waktu (Dusak Komunikasi Personal, 23 September 2019). Padewasan merupakan bentuk orang Bali menyikapi waktu. Dalam kalender Bali, Ala Ayuning Dewasa dijabarkan setiap harinya dalam satu bulan Masehi. Seperti contoh pada bulan April 2019 di tanggal 1 tertulis Samparwangke, Kaleburau, Kepadan, Kl. Nanggung, Kl. Luang, Kl. Sudukan, Kl. Wilkapa, Kl. Siung, Rk. Nujupati. Ps. Separsa. Ala Ayuning Dewasa bentukan hasil teoritis dan praktis dari menyadur wariga dewasa. Sebagai contoh jika menginginkan pengetahuan mengenai pitra yadnya diusahakan pecariannya dengan salah satu sumber hitung adalah wewaran kala buingrawu (Swandana et al., 2017).

Kemudian dalam profesi atau kegiatan tertentu seperti yang tersebut di atas, akan disebutkan tanggal yang dimaksudkan hari baik pada bulan tersebut. Masih pada bulan yang sama, pada profesi pertanian adalah membibit/ menanam padi: $8,11,14,20$, 26; menanam aneka tanaman: 5, 21, 22, 23, 25, 27; membuat bibit: 2, 11, 14, 23, 29; menanam buah-buahan: 23, 25; menanam palabungkah: 10, 17, 24, 25, 29; menanam penghasil daun: 2, 9, 16, 17, 23, 30; menamam bunga-bungaan: 3, 10, 17; menanam palawija: 4, 8, 11, 17, 18, 23, 25, 26, 29; menanam palagantung: 11, 23; menanam palarambat: 6, 13, 20, 27; menanam sarwabuku: 7, 11, 14, 21, 28, 29; biukukung: 5, 10, 11, 26; memetik: 2, 13, 20, 23, 26, 29; menyimpan padi di lumbung: 5, 26; menurunkan padi dari lumbung: 11 ; mantenin padi di lumbung: 10, 26; memasang kambat di sawah: 5, 16, 20; memasang tanda larangan: 1, 5, 16, 17, 20; membuat alat pertanian: 7, 8, 10,11, 14, 16, 23, 24; mengiris: 24 . Tampilan ini memberikan kita informasi bagaimana khazanah kewaktuan yang telah dituliskan hari baiknya menjadi pedoman aspek berbagai profesi. Bahkan tidak hanya itu, dalam beberapa kegiatan terdapat detail langkah yang dilakukan dan hari baiknya dilakukan contohnya seperti pada pertanian di atas.

Setelah kolom hari baik, dalam tulisan berwarna merah diimbau bahwa Ngaben dadakan dalam kurun waktu 7 hari, mulai dari hari meninggalnya; hindari pasah, rerainan, kl. gotongan, semutsadulur, penanggal/ panglong Ping 14 dan 15, Naganaut, wapenganten, kekeran jagat, kekeran desa, patirtan di Pura setempat. Selanjutnya setelah membahas tampakan depan pada kalender Bali, kemudian di bagian belakang sekitar 5-6 halaman belakang kalender dimuat informasi tambahan yang dapat membantu pemahaman terhadap kalender Bali. Informasi yang ditampilkan antarpenyusun dan antartahun berbeda.

Pada Kalender Bali Wayan Gina di tahun 2019, lembar belakang pertama, yakni di balik bulan Desember dijelaskan mengenai Pacaron Dewasa, Dawuh Ayu, dan Dawuh Banyu Sakaranti. Pacaron Dewasa atau Pamarisudaning Dewasa merupakan upaya untuk memusnahkan pengaruh buruk yang mungkin hadir dengan melakukan pertimbangan pada Wewaran alah dening Wuku, Wuku alah dening Panglong, Panglong alah denih Sasih, Sasih alah dening Dawuh, Dawuh alah dening Tryodasa Saksi menurut Wariga Dewasa karya Sri Reshi Andakumusa.

Dawuh Ayu adalah satu harinya dibagi menjadi 16 dawuh dengan komposisi masing-masing adalah 1 jam 30 menit. Siang dengan 8 dawuh sejak terbitnya matahari dawuh I-VIII, sedangkan malam juga 8 dawuh mulai terbenam matahari dawuh VIII-I. Untuk malam, bilangan dawuh mundur. Merupakan akumulasi dari waktu baik dari Panca Dawuh dan Asta Dawuh. Di halaman selanjutnya, yakni di balik bulan November, terdapat informasi tentang pengaruh $W u k u$ terhadap kelahiran, dan pengaruh Zodiak Gugusan Bintang terhadap kelahiran. Selain itu juga dijabarkan mengenai Surat Keputusan Bersama Menteri Agama, Menteri Ketenagakerjaan, serta Menteri Pendayagunaan Aparatur Negara dan Reformasi Birokrasi RI, yang mana membahas mengenai hari libur dan cuti 
bersama yang berlaku secara nasional. Keduanya, penjelasan mengenai $W u k u$ dan Zodiak di atas, merupakan sebuah upaya untuk membaca karakter dan kehidupan manusia melalui waktu kelahiran berdasarkan zodiak atau Wuku tertentu.

Lainnya adalah dijelaskan mengenai pengaruh pratithi samutpada terhadap kelahiran, penjelasan palalintangan, pal srigati atau ramalan pasang surut kehidupan, $n$ patemon lanag istri mengenai ramalan perjodohan, hingga baik buruknya posisi pintu pekarangan rumah dan waktu pindah. Melihat muatan informasi dan kekayaan budaya yang dikandungnya, membuat kalender Bali tidak hanya sebuah dokumentasi waktu saja, melainkan juga simbol universalitas, multikultur, multireligius dalam aspek kultur-religi, kultur-sosial, juga kepercayaan kuno akan mistisme.

\section{Nalar Fungsi dan Eksistensi Kalender Bali dalam Masyarakat Multireligius}

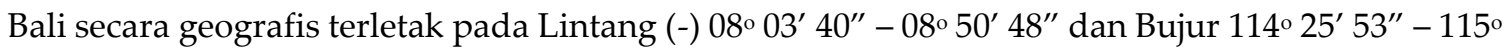
42' 40" dengan luas area adalah 5636.66 km² (Badan Pusat Statistik Provinsi Bali, 2018a). Bali dikenal sebagai daerah dengan mayoritas Hindu dan kekhasan budaya yang tetap ajeg dipertahankan. Meski demikian kalender Bali memiliki komposisi penduduk dengan ragam etnis dan agamanya. Lacakan sejarah berbagai migrasi etnis, menjadi sumbangsih kehadiran ragam agama dan budaya. Pada komunitas Muslim, misalnya mula kehadiran Islam masa awal adalah di daerah Klungkung. Kerajaan Gelgel diperintah oleh Dalem Waturenggong dengan cakupan wilayah hingga Sasak, Lombok, Sumbawa, dan Blambangan. Kerajaan ini dianggap sebagai estafet kerajaan Hindu pasca Majapahit (Ardhana et al., 2011).

Berdasarkan cerita yang berkembang di masyarakat dan juga penuturan salah seorang tokoh Muslim Klungkung (Barzain, Komunikasi Personal, 20 Agustus 2019). Ketika masa Kerajaan Gelgel dipimpin oleh Raja Dalem Waturenggong, disebutkan bahwa dalam suatu kesempatan raja bertandang ke Majapahit. Pasca kunjungan tersebut, raja didampingi oleh sekitar 40-an pendamping yang telah beragama Islam. Hubungan baik yang terjalin selama perjalanan membuat raja kemudian memberikan tanah adat kepada 40 orang tersebut di tanah dekat dengan puri. Tanah tersebut kemudian menjadi pemukiman mula Islam di Bali.

Selain Islamisasi, disebut juga upaya Kristenisasi yang terjadi di Bali. Dilakukan upaya yang panjang dalam memperkenalkan Kristen di Bali, sehingga titik baliknya disebut ketika I Gusti Wayan Karangasem memeluk Kristen dan mengganti nama menjadi Nicodemus, sebagaimana yang diungkap Jacob de Vroom. De Vroom sendiri merupakan salah satu tokoh yang memiliki tujuan upaya kristenisasi bersama dengan R Van Ech. Keduanya bertugas di Jagaraga, Singaraja selama kurang lebih 7 tahun. Setelah meninggalnya R Van Ech kemudian De Vroom melanjutkannya bersama K. Wiggelen. Namun kemudian di tahun 1881 De Vroom mati terbunuh (Ardhana et al., 2011)

Manusia, masyarakat, dan kebudayaan berkait secara dialektik. Ketiganya hadir atas lainnya dengan saling menciptakan dan meniadakan (Kahmad, 2009). Sehingga tanpa salah satu akan terjadi ketimpangan. Masyarakat didefinisikan oleh Koentjaraningrat adalah kesatuan manusia yang hidup dan berinteraksi menganut pada sistem adat tertentu yang kontinu sehingga terikat pada identitas serupa (Ardhana et al., 2011). Bali dengan kemasyhuran budayanya, hadir membersamai kehidupan masyarakatnya. Pun juga kalender Bali sebagai salah satu produk kebudayaan. Kebudayaan menurut Soemardjan dan Soelaeman Soemardi merumuskan kebudayaan sebagai produk dari karya, rasa, dan cipta masyrakat. Karya masyarakat menciptakan kebudayaan kebendaan untuk mengembangkan kemanusiaannya (Pujileksono, 2016).

Dalam upaya pengembangan aspek manusia ini, kemudian penulis mencoba membaca kalender Bali berbagai sektor kehidupannya.

\section{Religius}

Agama adalah instrumen urgen dalam masyarakat. Kesemua hal yang terkait dengan hubungan kehambaan antara manusia dengan Tuhan seperti seremoni perayaan, relasi antar dan interumat beragama, dan laku manusia atas alam dan implementasinya dipadatkan dalam simbolis dalam ritus Agama. Dalam Hindu, kalender tidak hanya organisasi waktu, namun juga sebagai aspek sakral yang 
mengatur elemen ritus. Seperti contoh penentuan odalan dan rainan, atau mengetahui waktu-waktu upacara dan Hari Raya, waktu ngaben dan sebagainya. Odalan merupakan peringatan diresmikannya sebuah bangunan Pura atau Pelinggih tertentu (Dusak Komunikasi Personal, 23 September 2019).

Dalam kalender oleh Wayan Gina, pada bulan Masehi tertentu akan dijabarkan Pura yang mengadakan odalan dengan terlebih dahulu menyebut kombinasi antaranya Saptawara, Pancawara, dan Wuku. Seperti contoh pada bulan September 2019, odalan di Pura terjadi pada tanggal 3, 7, 8, 11, 14, 17, 18, 21, dan 30. Pada tanggal 3, Anggara, Umanis, Krulut terjadi Odalan di Pura Petitenget Kerobokan Badung dan Pura Bhujangga Weisnawa Gumbrih Jembrana. Selain itu dalam menentukan Hari Raya Nyepi yang jatuh pada tahun baru Caka, atau menentukan Hari Raya Galungan yang jatuh setiap Wuku Dungulan, dengan Saptawara adalah Buda dan Pancawara adalah Kliwon. Sedangkan hari raya Kuningan adalah dengan kolaborasi Kuningan, Saniscara, Kliwon.

Sektor ini tidak hanya terbatas ruang lingkupnya pada umat Hindu saja, namun juga pada umat agama lain. Salah satunya Islam. Hal ini dikarenakan kalender Hijriah sebagai salah satu urgensi dalam peribadatan umat Islam seperti pelaksanaan ibadah Haji, Hari Raya Idul Fitri dan Idul Adha, Puasa Ramadan, juga tersebut dalam kalender Bali. Pun juga pada agama Kristen, Budha, Kong Hu Cu yang kalendernya juga merupakan bagian dari kalender Bali. Diantara aspek religius lainnya yang tersebut adalah seperti Hari Raya Waisak, Kenaikan Yesus Kristus, Go Gwe Ceh, Sakramen.

Fluiditas merupakan pelenturan budaya ketika ia masuk dalam budaya lainnya. Sehingga terdapat kekaburan makna dari maksud asalnya (Kahmad, 2009). Kalender Bali sebagaimana maksud asalnya, utamanya dalam kalender Caka dan Pawukon-nya, bercorak agama dan budaya Hindu. Ragam etnis dan agama yang kemudian hadir mewarnai Bali, menghadirkan kekayaan khas dan meninggalkan kesan universalitas dan pengakuan akan eksistensi etnis dan agama lainnya. Meski secara pemaknaan, kalender Bali dalam aspek religiusitas menjadi kabur tujuannya jika dimasukkan dalam agama non-Hindu. Namun fluiditas budaya menghasilkan sebuah daya kreatifitas yang berkembang dari makna awalnya. Sehingga kekaburan bukan menjadi menghilangkan makna awal, melainkan mengembangkan, memperkuat budaya.

\section{Kultur/ Budaya}

Meskipun keseluruhan ekspresi kalender adalah kebudayaan, mengacu pada penejelasan Cliffort Geertz kebudayaan merupakan sistem simbol dari makna-makna, sehingga ia mengacu pada pola makna yang terwujud dalam simbol melalui turunalih secara historis (Pujileksono, 2016). Kaitannya dengan simbol dan pemaknaan historis, salah satu aspek yang dapat dibahas dalam kalender Bali adalah pemakluman watak dan sifat seseorang yang dapat digali melalui waktu seperti pada Wuku, Palalintangan, Pratithi Samutpada terhadap kelahiran. Secara internasional, membahas perwatakan dengan berdasar pada waktu kelahiran dikenal dengan penyematan atas waktu lahir dan rasi bintang. Namun di Bali, simbol yang hendak ditunjukkan atas kearifan lokalnya melakukan pemaknaanpemaknaan watak atas simbolik waktu.

Jika dalam zodiak terdapat 12 klasifikasi watak, dalam Wuku terbagi menjadi 30 yang diterjemahkan menjadi watak dan sifat seseorang, pada Pratithi Samutpada berjumlah 12, dan pada Palalintangan terdiri dari 35 bagian. Selain perwatakan hal lainnya yag serupa dengan di atas adalah Patemon Lanang Istri ramalan pasangan atau perjodohan. Berbeda dengan perwatakan di atas yang hanya cukup dengan mengetahui kapan waktu lahirnya, diperlukan rumus matematis tertentu. Meski mengambil contoh kecil dari Kalender Bali, sebagai salah satu permisalan unsur kebudayaan. Pada hakikatnya keseluruhan kalender Bali merupakan entitas budaya, relasi yang terbangun karena kalender Bali adalah budaya, sifat, karakter, dan kecenderungan buah dari pemahaman kalender Bali juga budaya.

Kalender Bali dan lingkup keberlakuannya di Bali menjadikan keterikatan budaya antara penduduk Bali dan kalender Bali. Sehingga, dalam berbagai urusan administrasi, sosial, menggunakan kalender Bali sebagai acuan. Hal ini dikarenakan kalender Bali memiliki beberapa acuan yang berlaku secara daerah, namun tidak ditetapkan secara nasional. Sebagai contoh dalam Hari Raya Galungan dan Kuningan, yang bertepatan dengan dua Wuku yaitu Dungulan dan Kuningan membuat beberapa 
instansi formal menetapkan cuti. Dan masa keberlakuan cuti adalah dua minggu. Dimulai dari Redite di Wuku Dungulan hingga Saniscara di Wuku Kuningan. Cuti tersebut dan peringatannya tidak termasuk dalam Surat Keputusan tiga Menteri mengenai hari libur dan cuti bersama.

Selain umat Hindu, tentu penganut agama lain yang juga terlibat secara sosial pada berbagai sektor juga merasakan kebijakan libur daerah ini. Penggunaan kalender yang bukan kalender Bali, tentu akan memberikan ketidaktepatan informasi yang dibutuhkan (Barzain, Komunikasi Personal, 20 Agustus 2019). Juga pada pelaksanaan hari-hari tertentu yang pemberlakuan liburnya hanya tingkat daerah. Aspek sosial menjadi salah satu yang terpengaruh terhadap eksistensi dan nalar fungsi kalender Bali.

\section{Sosial}

Kehidupan manusia tidak lepas dari interaksi antarsesama. Hubungan ini terjalin tidak hanya pada interkomunitas, juga antarkomunitas. Dan kalender merupakan salah satu aspek vital dalam ranah sosial yang mengatur formal kewaktuan.

Kalender Bali dan lingkup keberlakuannya di Bali menjadikan keterikatan budaya antara penduduk Bali dan kalender Bali. Sehingga, dalam berbagai urusan administrasi, sosial, menggunakan kalender Bali sebagai acuan. Hal ini dikarenakan kalender Bali memiliki beberapa acuan yang berlaku secara daerah, namun tidak ditetapkan secara nasional. Sebagai contoh dalam Hari Raya Galungan dan Kuningan, yang bertepatan dengan dua Wuku yaitu Dungulan dan Kuningan membuat beberapa instansi formal menetapkan cuti. Dan masa keberlakuan cuti adalah dua minggu. Dimulai dari Redite di Wuku Dungulan hingga Saniscara di Wuku Kuningan. Cuti tersebut dan peringatannya tidak termasuk dalam Surat Keputusan tiga Menteri mengenai hari libur dan cuti bersama.

Selain umat Hindu, tentu penganut agama lain yang juga terlibat secara sosial pada berbagai sektor juga merasakan kebijakan libur daerah ini. Penggunaan kalender yang bukan kalender Bali, tentu akan memberikan ketidaktepatan informasi yang dibutuhkan (Barzain, Komunikasi Personal, 20 Agustus 2019). Juga pada pelaksanaan hari-hari tertentu yang pemberlakuan liburnya hanya tingkat daerah. Aspek sosial menjadi salah satu yang terpengaruh terhadap eksistensi dan nalar fungsi kalender Bali.

\section{Ekonomi}

Nalar fungsi penting lainnya adalah ekonomi. Weber (2005) mengungkap bahwa kebudayaan masyarakat dapat menjadi kekuatan pendorong terhadap kemajuan ekonomi. Terkait hal itu, jika memperhatikan di Kalender Bali oleh Wayan Gina, terdapat garis biru lurus yang menandai setiap 3 hari. Tanda tersebut merupakan penegasan dalam kegiatan pekenan atau hari pasar buka.

Hari Pasar Buka ini merupakan kegiatan berdagang masyarakat Bali dengan cakupan pasar tertentu di suatu daerah dengan menggunakan pertimbangan hari pada Triwara. Jadwal pekenan diantaranya adalah sebagai berikut, Badung, Denpasar, Gianyar, dan Tegalalang terjadi pada hari Beteng; Bajra, Baturiti, Kapal, Kediri, Luwus, Payangan, Penelokan terjadi pada hari Kajeng, sedangkan Bangli, Klungkung, dan Ubud terjadi pada hari Pasah (Eiseman \& Elseman, 2012). Dalam Kalender Wayan Gina, hari yang ditandai adalah hari Pasah. Mengingat lokasi tinggalnya di daerah Karangasem, maka penandaan ini digunakan untuk menyatakan pekenan di Karangasem.

Pekenan tidak hanya penting bagi pedagang saja, namun keseluruhan aspek masyarakat Bali. Hal ini karena aktivitas ekonomi vital adalah pasar. Sehingga memandang hal tersebut, mengetahui dan memahami pola ini merupakan sebuah urgenitas masyarakat Bali. Selain pasar, aspek ekonomi lainnya seperti agraria, arsitektur, kesenian, kesehatan terangkum dalam hari-hari baik untuk melakukannya. Sebagaimana yang disebut sebelumnya, bahkan pada pertanian diatur sedemikian rupa proses dan kapan waktu terbaik melakukannya.

Contoh dalam berdagang, di Desember 2019 disebut bahwa mulai usaha dapat dilakukan di tanggal 3, 6, 7, 9, 19, 27. Mempersiapkan lokasi atau tempat yang digunakan untuk berdagang 3, 4, 7, 20, 27. Mulai berdagang 3, 9, 27. Membuat tempat harta, 1, 4, 6, 24. Dan membeli kendaraan atau trasnportasi operasional 3, 14, 18, dan 27. 
Kesemua aspek tersebut penulis anggap telah mewakili bagaimana urgenitas kalender Bali terhadap masyarakatnya. Sehingga eksistensinya tetap terjaga di tengah gempuran modernisasi, karena keterbutuhan dan penggunaannya hingga kini. Multireligius merupakan gambaran keragaman penganut agama yang tinggal berdampingan di Bali. Perbedaan agama tidak menghalangi keterbutuhannya akan kalender dari keseluruhan aspek. Sehingga hari ini, kalender Bali, oleh masyarakat Bali umumnya, menjadikannya sebagai pilihan utama kalender.

Meskipun dalam sejarahnya kalender Bali yang dimaksud adalah identik dengan budaya dan agama Hindu, namun pada perkembangannya himpunan dan universalitas kalender Bali menjadikannya inklusif tanpa memandang agama yang dianutnya.

\section{Conclusions}

Tulisan ini menghasilkan kesimpulan bahwasannya kalender Bali dikenal pada masa tradisi besar yang berorientasi pada agama Hindu dan kebudayaannya. Kalender Bali menghimpun berbagai sistem penanggalan seperti Masehi, Hijriah, Cina, Caka Bali, Budha, Jawa Islam, dan Pawukon. Sehingga menganut universalitas dan pengakuan komunitas etnis dan agama lain melalui muatan kalendernya. Nalar fungsinya kalender Bali tidak hanya terbatas digunakan oleh umat Hindu saja, namun juga oleh keseluruhan penganut dalam tataran multireligiusnya dari aspek religius, kultur, sosial, hingga ekonomi.

\section{Referensi}

Ardhana, I. K., Sunaryo, F. X., Sulandjari, I. P. G. S., \& Putra, I. B. G. (2011). Masyarakat Multikultural Bali: Tinjauan Sejarah, Migrasi, dan Integrasi (I). Pustaka Larasan.

Aveni, A., \& Hartung, H. (1986). Maya city planning and the calendar. Transactions of the American Philosophical Society, 76(7), 1-87.

Azhari, S. (2005). Ensiklopedi Hisab Rukyat. Pustaka Pelajar.

Azhari, S. (2015). Gagasan Menyatukan Umat Islam Indonesia Melalui Kalender Islam. AHKAM: Jurnal Ilmu Syariah, 15(2).

Badan Pusat Statistik Provinsi Bali. (2018a). Luas Wilayah dan Letak Geografis Pulau Bali. Badan Pusat Statistik Provinsi Bali. https://bali.bps.go.id/statictable/2018/04/10/47/luas-wilayah-dan-letak-geografis-pulau-balidan-kabupaten-kota.html

Badan Pusat Statistik Provinsi Bali. (2018b). Penduduk Provinsi Bali Menurut Agama yang Dianut: Hasil Sensus Penduduk 2010. Badan Pusat Statistik Provinsi https://bali.bps.go.id/statictable/2018/02/15/33/penduduk-provinsi-bali-menurut-agama-yang-dianut-hasilsensus-penduduk-2010.html

Chatterjee, S. K. (1997). Balinese Traditional Calendar. Indian Journal of History, 32(4).

Davenport, M. (2007). Calendar as Culture: An Interdisciplinary Project with an Indigenous Community. Journal of Cultural Research in Art Education, 25, 79.

Eiseman, F. B., \& Elseman, J. M. (2012). Fruits of Bali. Tuttle Publishing.

Firdaus, R. (2012). Nalar Kritis Terhadap Sistem Penanggalan Im Yang Lik. Institut Asama Islam Negeri Walisongo.

Ginaya, G. (2018). The Balinese Calendar System : From Its Epistemological Perspective to Axiological Practices. International Journal of Linguistic, Literature, and Culture, 4(3), 24-37.

Hidayatullah, S. (2018). Global Hijriyah Calendar as Challenges Fikih Astronomy.

Kahmad, D. (2009). Sosiologi Agama. PT Remaja Rosdakarya.

Khazin, M. (2008). Ilmu Falak dalam Teori dan Praktik. Buana Pustaka.

Muh Bashori, H. (2013). Penanggalan Islam. PT Elex Media Komputindo.

Mutamakin, M. (2018). Astronomi, Analisis Sistem Penanggalan Kalender Caka Bali dalam Perspektif. Universitas Islam Negeri Walisongo.

Nashirudin, M. (2013). Kalender Hijriah Universal. El-Wafa.

Prawira, I. P. C., Sasmita, G. M. A., \& Bayupati, I. P. A. (2015). Pengembangan Aplikasi “ Kalender Saka Bali ” pada Sistem Operasi Machintos. Merpati, 3(2), 58-67.

Pujileksono, S. (2016). Pengantar Antropologi Memahami Realitas Sosial Budaya. Intrans Publishing.

Ramdhani, F. Z. (2017). Analisis Sistem Penanggalan Pawukon Bali. Universitas Islam Negeri Walisongo.

Rohmah, N. (2019). Dinamika Almanak Masa Pra Islam Hingga Era Islam; Studi atas Penanggalan Sistem Solar, 
Lunar dan Luni-Solar. QALAMUNA: Jurnal Pendidikan, Sosial, Dan Agama, 11(2), 157-172.

Sorokin, P. A., \& Merton, R. K. (1937). Social time: A methodological and functional analysis. American Journal of Sociology, 42(5), 615-629.

Suarka, I. N. (2008). Sistem Penanggalan Bali. Makalah Seminar Nasional Menelusuri Sistem Penanggalan Nusantara. Sulistiono, B. (2018). Kearifan Lokal di Tengah Masyarakat Muslim di Propinsi Bali: Studi Toleransi. Jurnal Sejarah, 02(1), 53-72.

Swandana, I. W., Mahendrayana, G., Gede, L., \& Wahyuni, E. (2017). Pemaknaan Tanda dalam Ala Ayuning Dewasa Berdasarkan Wewaran pada Kalender Caka Bali. Seminar Nasional Riset Inovatif II, 88-92.

Swellengrebel, J. L. (1960). Bali: some general information. W. van Hoeve.

Weber, M. (2005). Remarks on technology and culture. Theory, Culture E Society, 22(4), 23-38.

Wiana, I. K. (2003). Wewaran / Pewarigaan. Babad Bali. https://www.babadbali.com/pewarigaan/pewarigaan.php

(C) 2020 by the authors. Submitted for possible open access publication under the terms and conditions of the Creative Commons Attribution (CC BY SA) license (https://creativecommons.org/licenses/by-sa/3.0/). 